\title{
Comparative scanning electron microscope study of the degradation of a plasticized polyvinyl chloride waterproofing membrane in different conditions
}

\author{
A. Pedrosa $\bowtie$, M. Del Río \\ Escuela Técnica Superior de Edificación de Madrid, Universidad Politécnica de Madrid (Madrid, Spain)
}

\a.pedrosa@alumnos.upm.es

\author{
Received 23 October 2015 \\ Accepted 9 June 2016 \\ Available on line 20 January 2017
}

\begin{abstract}
This paper discusses the analysis of several samples of a plasticized polyvinyl chloride (PVC-P) waterproofing membrane. The samples were extracted from different areas of the same flat roof, which was in service for over 12 years. An original sample of an identical PVC-P membrane that was not installed on the roof was also analyzed. The analysis of the materials was carried out using a scanning electron microscope (SEM). An elemental analysis of every sample was also performed by energy dispersive X-ray spectroscopy (EDS). Micrographs and the elemental composition of the samples were compared with the data obtained in the analysis of the original sample. The results show dehydrochlorination of the polymer in two of the samples studied and great deterioration that was not visible to the naked eye in the sample that was totally exposed to the weather.
\end{abstract}

KEYWORDS: Dehydrochlorination of PVC; Polymer; PVC-P weathering; Durability; Scanning Electron Microscopy (SEM)

Citation/Citar como: Pedrosa, A.; Del Río, M. (2017) Comparative scanning electron microscope study of the degradation of a plasticized polyvinyl chloride waterproofing membrane in different conditions. Mater. Construcc. 67 [325], e109. http://dx.doi.org/10.3989/mc.2017.08915

RESUMEN: Estudio comparativo con microscopio electrónico de barrido de la degradación de una lámina impermeable de cloruro de polivinilo plastificado en diferentes condiciones. Este estudio discute el análisis de varias muestras de una membrana impermeable de cloruro de polivinilo plastificado (PVC-P). Las muestras fueron extraídas de diferentes áreas de la misma cubierta plana, que estuvo en servicio durante más de 12 años. Una muestra original de idéntica membrana de PVC-P que no estuvo instalada en la cubierta fue también analizada. El análisis de los materiales se llevó a cabo utilizando un microscopio electrónico de barrido (MEB). Además se realizó un análisis elemental sobre cada una de las muestras mediante espectroscopía de dispersión de energía de rayos X (EDS). Las micrografías, y la composición elemental de las muestras, se comparan con los datos obtenidos en el análisis de la muestra original. Los resultados muestran deshidrocloración del polímero en dos de las muestras estudiadas, y un gran deterioro de la muestra totalmente expuesta a la intemperie, que no era visible a simple vista.

PALABRAS CLAVE: Deshidrocloración de PVC; Polímero; Envejecimiento del PVC-P; Durabilidad; Microscopía Electrónica de Barrido (MEB)

ORCID ID: A. Pedrosa (http://orcid.org/0000-0002-7477-6288); M. Del Río (http://orcid.org/0000-0002-4106-4233)

Copyright: (C) 2017 CSIC. This is an open-access article distributed under the terms of the Creative Commons Attribution License (CC BY) Spain 3.0. 


\section{INTRODUCTION}

There are a number of mechanisms by which waterproofing membranes degrade, some of which have already been studied. The deterioration of waterproofing membranes will at some point imply the end of the life cycle of the entire construction solution. When a waterproofing system cannot ensure the absence of damp or leaks in the rooms that it covers, the construction system must be repaired. Sometimes the flat roof will have to be renovated completely, and this might include having to demolish paving materials, refurbish installations and invest a great deal of labor in moving layers of protection such as geo-textiles, gravel, and plants and soil in the case of green roofs.

This is not a chemical study, although the deterioration caused by direct exposure to the weather of a PVC-P waterproofing membrane was analyzed. This condition is compared with the degradation of a PVC-P waterproofing membrane in direct contact with an extruded polystyrene (XPS) board in an inverted flat roof.

An inverted flat roof is any flat roof in which thermal insulation covers the waterproofing material. It is a widely used solution. Thermal variations of waterproofing membranes are limited substantially by the position of the insulation material in the construction system. Thermal insulation in inverted flat roofs must have certain properties, such as not absorbing water and resisting the action of microorganisms. Water absorption results in lost insulation power ( $\mathrm{R}$ value). The insulation material that is currently used in inverted flat roofs is extruded polystyrene board (water absorption is less than $0.3 \%$ by volume, according to ASTM C578). There is no alternative, as no other insulation material has the required properties.

On the other hand, crude polystyrene can, in favorable conditions, absorb plasticizers added to PVC-P in the manufacturing process; in fact, polystyrene is used in chemical studies and tests as an absorbent material of plasticizers in PVC-P sheets (1).

The ASTM D883 standard defines a plasticizer as: a substance incorporated into a plastic or elastomer to increase its flexibility, workability or distensibility (2). Thus, plasticizer loss has important consequences for waterproofing membranes, and although compatibility between XPS and PVC-P is not fully understood, XPS is also capable of absorbing plasticizers in PVC-P waterproofing membranes (3). This may be considered an incompatibility type.

The waterproofed surface of the roof from which the samples were taken was made with the same type and brand of PVC-P membrane. Therefore, all of the samples were initially identical; however, as is usually the case, the membrane was installed in different areas of the roof.

Normally, in every flat roof, waterproofing membranes are laid in different areas, covering distinct construction elements totally or partially, and they are therefore subject to different conditions.

Figure 1 shows a detailed drawing of the two conditions studied in this paper. The images show the position of the samples extracted from the roof. In image (A), a cross section of the first condition

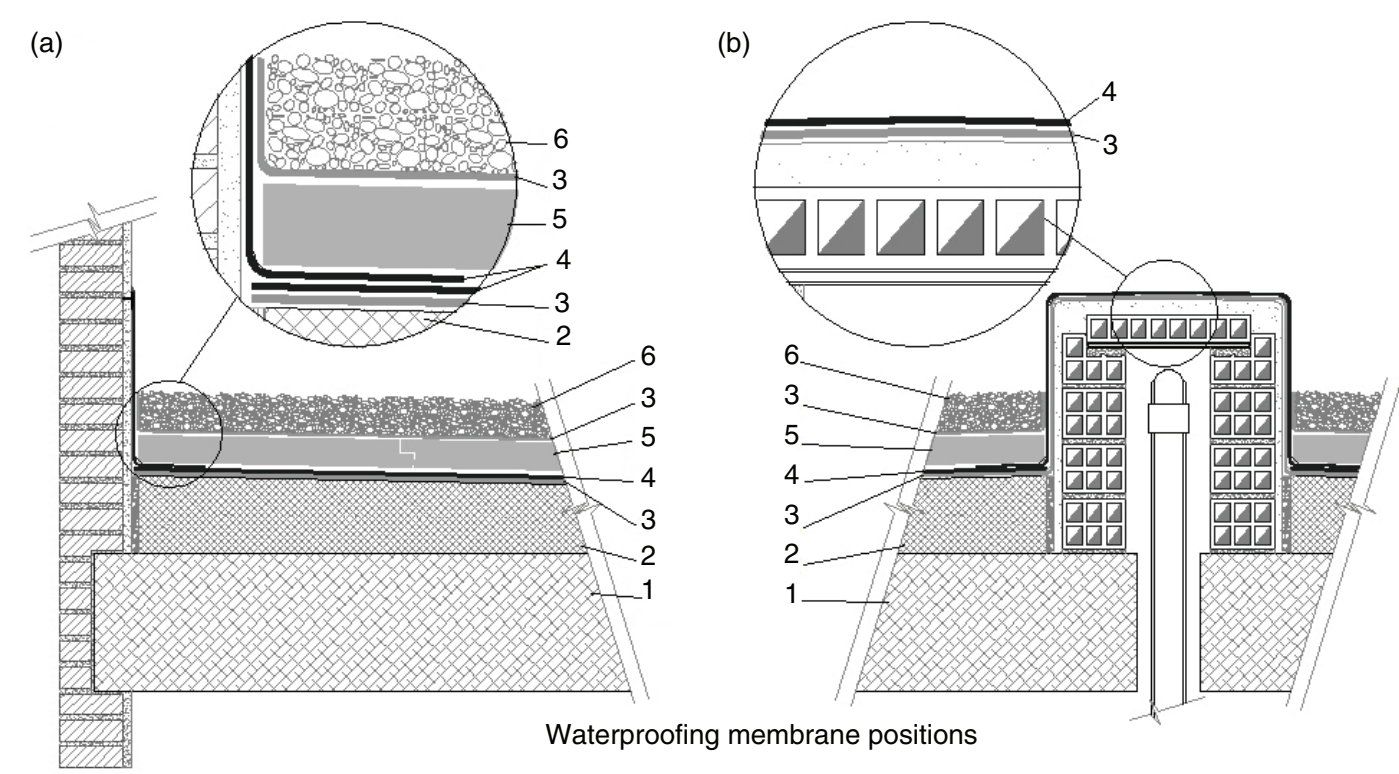

FIGURE 1. Detailed drawing (cross section) of the positions of the samples extracted from the flat roof. In the image on the left the first condition (A) is shown (samples taken from the inverted flat roof area). In the image on the right the second condition (B) is shown, which is a sample totally exposed to natural weathering in the horizontal position. Nomenclature: 1 - Slab; 2 - Slope formation; 3 - Auxiliary separating sheet; 4 - PVC-P waterproofing membrane; 5 - XPS; 6 - Gravel protection layer. 
is shown (inverted flat roof). A detail of the second condition can be seen in image (B); this was totally exposed to the weather in the horizontal position. Both images show details of the precise area from which the samples were extracted.

Using a scanning electron microscope (SEM), the material's surface can be studied at various magnifications. Additionally, some devices can analyze the elemental composition of the observed samples by energy dispersive X-ray spectroscopy (EDS) analysis.

In order to obtain data on the degree of deterioration of each sample, the microscopy and the elemental analysis were also performed on an original sample of an identical PVC-P waterproofing membrane (that was not installed in the flat roof).

\section{OBJECTIVE}

The objective of this study is to analyze the ways in which a PVC-P waterproofing membrane may deteriorate. The most damaging or degrading set of outdoor conditions (a horizontal position in a sunny area) is compared with the deterioration that occurs by direct contact with an extruded polystyrene (XPS) board in an inverted flat roof.

\section{STATE OF THE ART}

Waterproofing membranes degrade in a variety of ways, although the degradation mechanisms that play a part are common to most of these membranes. Artificial methods for accelerating and testing deterioration have been used to estimate the performance of different types of waterproofing membranes $(4,5)$. Exposure to radon gas is one of these artificial methods. In the long term, radon gas may affect the mechanical properties of some waterproofing membranes (6). Prolonged exposure to heat (in which time and temperature are often varied) is also a common method for testing the functionality and durability of a waterproofing membrane.

In the case of PVC-P, a method that is frequently used is exposure to UV lamps (e.g. xenon lamps) (7). Sometimes, a cyclic spray of distilled water is applied to one side of the specimen sheet (8), in addition to UV radiation. Artificial thermal ageing tests are also common. They are typically performed in ventilated ovens and at variable temperatures, depending on the type of material under study. This procedure may include different atmospheres in the test, such as nitrogen or air (9). Plasticizer migration tests are also used with PVC-P (1). Polymers may deteriorate because of the loss of plasticizer.

Standards also describe simulated accelerated weathering tests to study the damaging effects of long-term outdoor exposure of materials and coatings. Examples are the ASTM G154, developed for operating fluorescent ultraviolet (UV) lamps with nonmetallic materials (10), the ASTM D432913 for testing plastic materials (11) and the ISO 4892-2:2013, which specifies methods for exposing specimens to xenon-arc light in the presence of moisture in order to reproduce weathering effects (temperature, humidity and/or wetting) (12).

Laboratory weathering tests under controlled conditions give fast predictions of a material's durability as an approximation of real use behavior. However, natural ageing processes are the most realistic way of studying a material's deterioration. In natural conditions, the main factor in the deterioration of waterproofing membranes is radiation from the sun (UV radiation) (13).

Most waterproofing membranes are polymers (3); the degradation of polymers includes changes in both their chemical structure and their physical properties. These changes tend to worsen the initial properties of the material.

Polymer deterioration includes biodegradation, pyrolysis, oxidation, mechanical, photo and catalytic degradation. Polymers are vulnerable to harmful effects from the environment. Oxygen and its active forms, humidity and atmospheric pollutants such as nitrogen oxide, sulfur dioxide and ozone all affect the properties of polymers in the long term, as do physical processes such as thermal expansion and contraction, mechanical stress and UV radiation (14).

The degradation of PVC has been widely studied since 1940. Some causes of deterioration of PVC-P (e.g. high temperature and UV radiation) result in two main degradation processes: the dehydrochlorination and the discoloration of the polymer (15), which are related to each other (16). In the process of dehydrochlorination, most of the $\mathrm{Cl}$ is released as hydrogen chloride $(\mathrm{HCl})$. This $\mathrm{HCl}$ is accompanied by small amounts of hydrocarbons, mainly aromatics such as benzene $(14,17)$.

At high temperatures (around $300{ }^{\circ} \mathrm{C}$ ), the resulting dehydrochlorinated polyene chain undergoes scission and the subsequent formation of benzene and other aromatic (and aliphatic) hydrocarbons (18).

A correlation between the kinetics of the thermal dehydrochlorination of PVC and the structure of this macromolecule has been demonstrated (19). Cross-linking and chain-scission reactions affect the physical properties of degraded PVC. Crosslinking results in high molecular weight (stiff polymers), while chain scission reduces the molecular weight, thereby increasing solubility.

Several factors must be taken into account in order to understand the complexity of the environmental deterioration of waterproofing membranes in flat roofs. These factors are summarized below. 
- Weathering - Natural ageing

This is the most important and common way in which waterproofing membranes deteriorate. It includes many others, such as solar radiation (UV radiation) (20), high temperatures, freezethaw cycles, water $(13)$, hail $(21,22)$, oxidation processes, etc. Even wind can sometimes compromise the integrity of a waterproofing membrane $(23,24)$.

In addition, regardless of the position of a waterproofing membrane (exposed to the elements, protected with covering layers, in the presence of oxygen or not, etc.), these materials undergo visible deterioration over time.

- Other factors

Other factors can cause degradation in a waterproofing membrane. The main aspect in this group is interaction with other materials and environments. Waterproofing membranes can interact with pollution, dust and other materials, such as polystyrene (25) and petroleum products (26). The action of microorganisms (4), for which a flat roof can be the perfect breeding ground, is also important. Interaction with XPS is another cause of deterioration of waterproofing membranes. Three factors are involved in the interaction between PVC-P waterproofing membranes and XPS: contact, heat and pressure (3).

\section{MATERIALS AND METHODS}

First, three samples of PVC-P waterproofing were extracted from a 12-year-old flat roof (located in Madrid, Spain), as described in Figure 1. Two of these samples came from areas with the configuration of an inverted flat roof; this was covered or protected by extruded polystyrene (XPS) board, as Figure 1 shows (position A). One was taken from an area of the roof with significant incidence of solar radiation; the other came from a shaded area (with no direct sunlight).

The areas of extraction of these two samples were chosen in different areas of the roof, because of the proven influence of temperature on the interaction with the extruded polystyrene board (3). They were not exposed to direct sunlight, since they remained covered by the XPS and protection layers. The prediction is that the samples would show varying states of conservation.

The third sample was extracted from an area with a high influence of solar radiation; the sample was directly exposed to weathering (position B in Figure 1). Due to the horizontal position of the sample, the influence of the elements would have been more damaging to the integrity of the PVCP. In other words, the action of ice, hail and UV radiation from the sun would have had a greater influence on the surface and the internal structure of the sample than other vertical outdoor positions of the membrane.

Figure 2 shows the sunny areas from which two of the samples were taken. Image (A) shows the first condition analyzed (position A in Figure 1); image (B) shows the second (position B in Figure 1). Note that this sample was located away from the influence area of XPS.

Figure 2 shows the extraction areas once the samples had been taken and the areas had been patched with a compatible material. Every sample drawn from the roof had to be repaired immediately. Before that, to make welding easier, the contact surface between the new and the old membranes (overlap) was cleaned with ethyl acetate, as can be seen in the photographs. The images show the PVC-P waterproofing membrane (a),
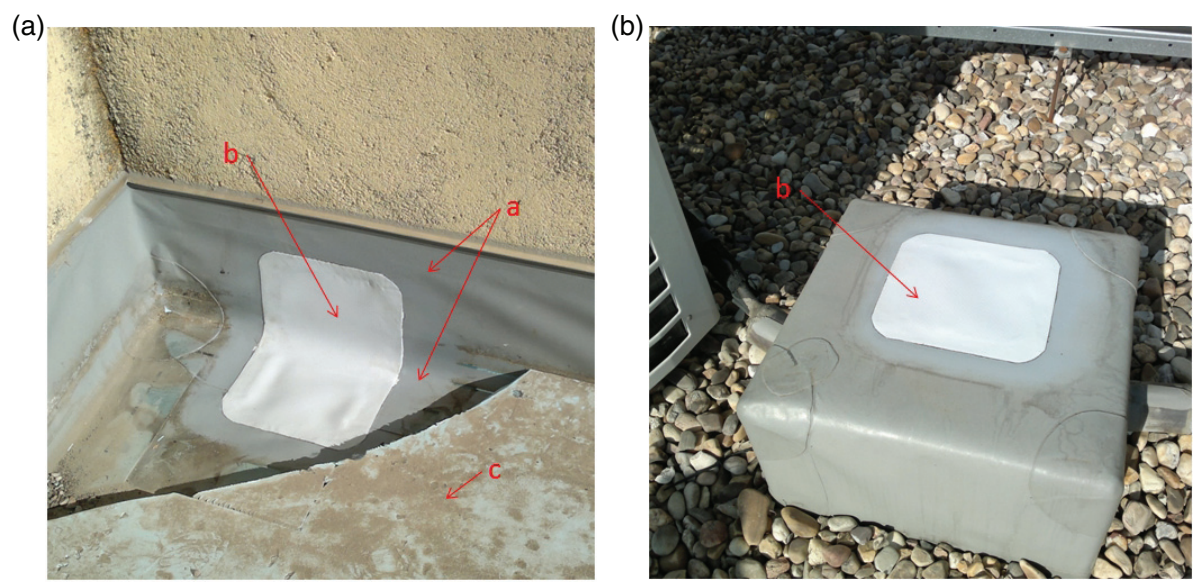

FIGURE 2. The images show the sunny areas from which two of the samples were taken once they had been repaired. In image (A), the first condition is presented (position A - Figure 1); in image (B), the second condition is presented (position B - Figure 1). Nomenclature: a - PVC-P waterproofing membrane; $b$ - Patch of PVC-P compatible material covering the gap of the sample previously extracted; c - XPS. 
the patch of PVC-P (b) covering the gap where the sample had been taken and the XPS (c).

Microscopic analysis was carried out with a JEOL JSM 6400 scanning electron microscope at the National Center of Electron Microscopy, Complutense University of Madrid, Spain.

The accelerating voltage was $20 \mathrm{kV}$ and the working distance was $15 \mathrm{~mm}$. With these parameters the SEM has a resolution estimated at $5 \mathrm{~nm}$. The resolution of the images used was 1024 x 786 pixels.

Since the material studied with the microscope is not conductive, it was necessary to make a sample preparation with gold coating beforehand.

The SEM is equipped with an energy dispersive spectrometer with a resolution of $133 \mathrm{eV}$. EDS is a qualitative and quantitative X-ray micro-analytical technique that provides information on the chemical composition of a sample. In SEM-EDS analysis, an electron beam reaches the surface of the sample and interacts with the atoms from which it is made; the analysis is carried out by collecting characteristic X-rays generated by the ionization of inner electron shells followed by transitions of outer electrons (relaxations). The surface of the sample (atoms) emits two types of radiation: continuum or background X-rays (which are mathematically corrected and filtered) and characteristic $\mathrm{X}$-rays (which are useful for studying the nature of the surface).

The PVC-P waterproofing membrane analyzed has an internal fiberglass fabric reinforcement to provide dimensional stability to the membrane. Glass fibers are included in the mass of PVC-P; thus, the internal reinforcement is actually a PVC-P fiberglass fabric, with a thin covering of PVC-P on both sides of the waterproofing membrane.

EDS analysis is a proven method for studying the composition, distribution of elements and phases of materials, and it is appropriate to study the composition of the PVC-P sample without interferences from other materials.

Establishing the error of the measurements obtained by EDS is a complex task. In EDS analysis, sources of error may be related to the sample, the microscope, the EDS detector or the data reduction software. It is difficult to quantify all of the sources of error; however, the analytical processes were performed successfully and no errors occurred in the analysis. Considering operational EDS parameters and possible combined errors, the precision of the EDS analysis can be estimated to be $\pm 2 \%$ for major components.

Three areas were studied in the two samples taken from position A (Figure 1: shaded and sunny samples): one in the sample extracted from the shaded area, and two areas in the sample from the sunny area. One of them had remains of interaction with the XPS, and the other did not; these remains were removed before the chemical analysis.
Finally, another original (that was not taken from the flat roof) and identical sample of the PVC-P waterproofing membrane was analyzed with the SEM-EDS. The waterproofing membrane was Rhenofol ${ }^{\mathbb{B}}$ CG 1,2 made by FDT.

The five areas analyzed with the scanning electron microscope are named as follows.

- Position A (Figure 1):

- 1cXPSsunnyInter - Sunny area, interaction with XPS.

- 2cXPSsunnyNOInter - Sunny area, without interaction with XPS.

- 3cXPSshaded - Shaded area, without interaction with XPS.

- Position B (Figure 1):

- 4H-exposed - Sunny area in outdoor horizontal position.

- Original and identical sample of the PVC-P waterproofing membrane:

- 5Original - Sample of the PVC-P (not installed in the flat roof).

This study ends with an analysis, comparison and discussion of the results of the chemical and microscopic analyses.

\section{RESULTS AND DISCUSSION}

\subsection{Analysis of scanning electron micrographs}

The analysis of the micrographs is presented in pairs, comparing 5Original with 2cXPSsunnyNOInter and 3cXPSshaded, respectively.

Figure 3 shows the comparison between the 3cXPSshaded micrograph (in the upper half of image 3) and 5Original (in the lower half of image 5), both at 1000 magnification. Micrographs are slightly different; they present a surface with elongated and rounded edge shapes, which have a lighter color than the rest of the surface. To make it easier to identify them, some are marked with red lines. Color variations in the surface of every sample are directly related to the sample's surface topography. When the incident beam scans across a bulge (a more elevated area) the amount of secondary electrons that can escape the sample surface is greater than the one emitted from the deeper zones (valleys). This suggests that the relief of the sample has been flattened due to weathering, i.e. the polymer surface has become more uniform because of the action of weathering. The images shown in Figure 3 were taken in secondary electron (SE) mode (a signal type produced by the SEM).

The color of the surface of sample 3cXPSshaded (Figure 3 - image 3 ) has become darker in comparison with the original sample (5Original in Figure 3 - image 5), making it difficult to distinguish the rounded and elongated shapes, which are much 

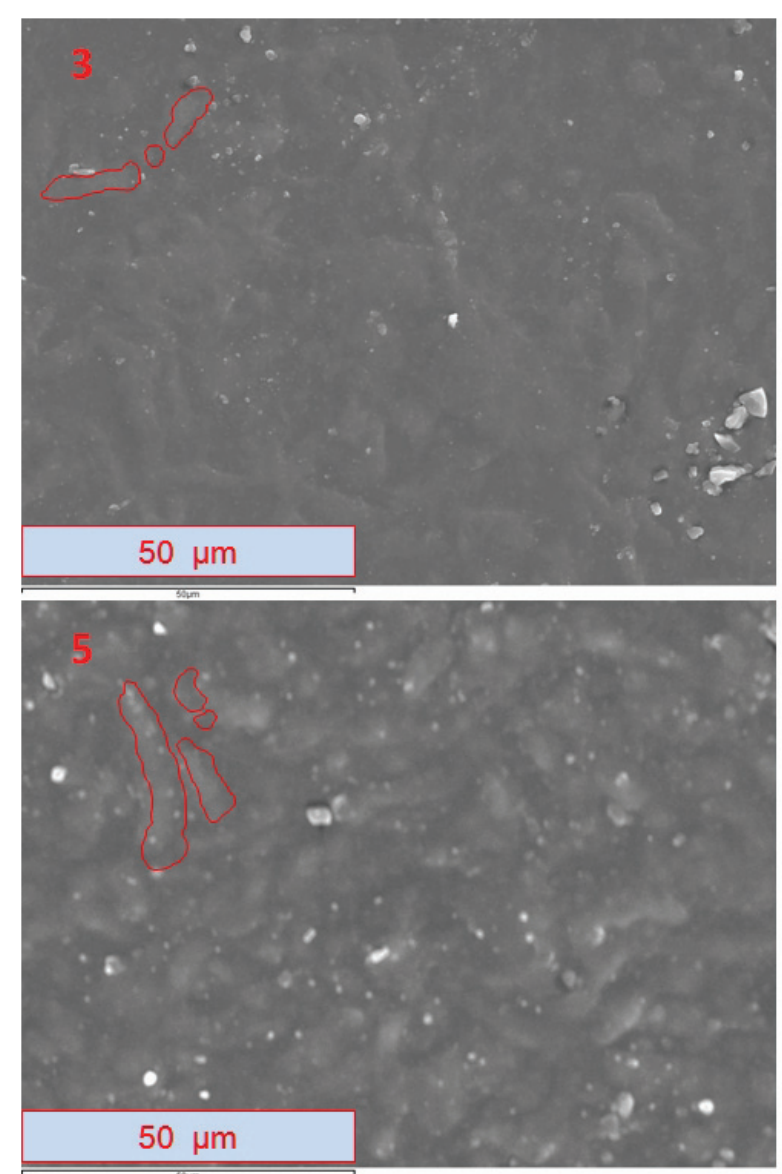

FIGURE 3. The image presents a comparison between micrographs at 1000 magnification. Micrographs were taken in (SE) mode with a resolution of $1024 \times 786$ pixels. Image 3 shows 3cXPSshaded; image 5 shows 5 Original.

clearer in the original sample. The 3cXPSshaded sample had remained under the extruded polystyrene (XPS) board, in a shaded area of the roof.

Figure 4 shows a comparison at 1000 magnification between 2cXPSsunnyNOInter (2) and 5Original (5). Micrographs were taken in SE mode.

The color of the surface of sample 2cXPSsunnyNOInter (Figure 4 - image 2) has become uniform and is much darker than it is in the original sample (5Original in Figure 4 - image 5). In certain areas of the 2cXPSsunnyNOInter micrograph, the characteristic rounded and elongated shapes of the polymer's surface are not visible. This sample remained under the XPS in a sunny area of the roof. The darker color of the sample in comparison with the one obtained in 3cXPSshaded (Figure 3 - image 3 ) is probably caused by higher temperatures in that part of the roof.

Figure 5 shows a single micrograph (taken in SE mode) of 1cXPSsunnyInter at 1000 magnification. In this image, the result or product of the interaction between the PVC-P and the XPS can be seen.

Direct contact between PVC-P and XPS may produce interaction (under certain conditions);
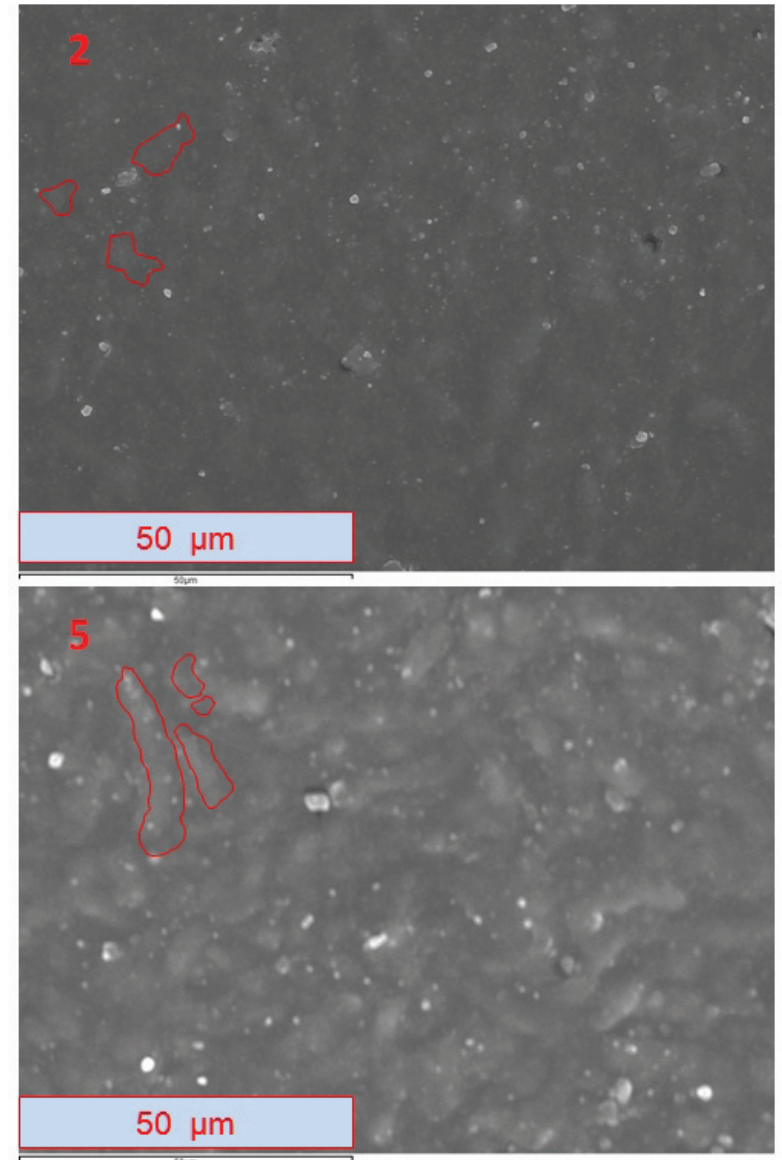

FIGURE 4. The image shows a comparison between micrographs at 1000 magnification: in image 2 ,

2cXPSsunnyNOInter; in image 5, 5Original. Micrographs were taken in (SE) mode with a resolution of 1024 x 786 pixels.

this interaction generates a product (3). Figure 5 shows an area in which the surface of the PVC-P waterproofing membrane might be identified, with its characteristic rounded and elongated shapes (marked in the photograph between red lines); however, no reliable data are available to assert it categorically.

Interaction between PVC-P and XPS implies a chemical reaction that transforms XPS (a plastic foam with low density) into a new material with greater density. This phenomenon involves a substantial volume variation in the XPS. The characteristics of the resulting material make its distribution irregular. Thus, on the surface of the PVC-P sample shown in Figure 5 there is no irregular interaction or lack thereof, but a consequence of interaction.

The last group of micrographs presented corresponds to the sample exposed to natural weathering $(4 \mathrm{H}$-exposed) in a horizontal position. The top half of Figure 6, image $4 \mathrm{a}$, shows the sample at 1000 magnification, and below, image 4b presents the same sample at 100 magnification. There are significant differences with the previous micrographs. 


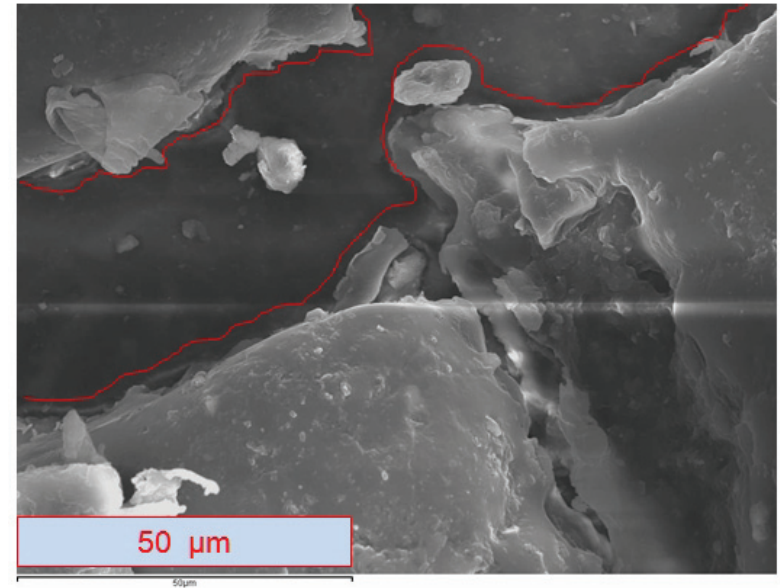

FIGURE 5. Micrograph of sample 1cXPSsunnyInter at 1000 magnification, with remains of interaction between PVC-P and XPS. The area enclosed by red lines is free of interaction remains. The micrograph was taken in (SE) mode with a resolution of $1024 \times 786$ pixels.

The surface of the polymer is substantially deteriorated and there are numerous cracks and fractures in its surface. Direct exposure to environmental elements caused great degradation in the polymer. The sample underwent a great incidence of direct solar radiation, as well as direct and prolonged exposure to harmful weather conditions such as hail, high temperatures and frost cycles.

In the bottom half of Figure 6 image $4 \mathrm{~b}$, many cracks and fractures can again be seen on the surface of the polymer. In addition to this, there are other erosions marked with red arrows. These circular shape erosions look like craters in the surface of the polymer and were probably produced by hail. Both micrographs were taken in SE mode.

Hail storms can be extremely damaging to waterproofing membranes that are directly exposed to environmental elements and in a horizontal position; specific tests are in fact carried out in current standards such as EN 13583 (27) or work item ASTM WK184 by ASTM International (28). Other standards such as DIN 16726, SIA V 280 and ASTM D3746 describe testing methods for determining the resistance to impact of roofing membranes.

Hail is especially harmful for waterproofing membranes if they are placed on a surface that is not rigid, for instance, an insulation material (rock wool, polystyrene, etc.). In this case, the waterproofing membrane has to resist greater stress because of the deformability of the base material (21); however, this is not the case of sample $4 \mathrm{H}$-exposed.

Another important factor must be taken into account in considering hail damage: the waterproofing membrane's age. This is the case of sample 4H-exposed: the aged waterproofing membrane has lost a great deal of its initial characteristics, meaning the material has lower resistance to deformation, has
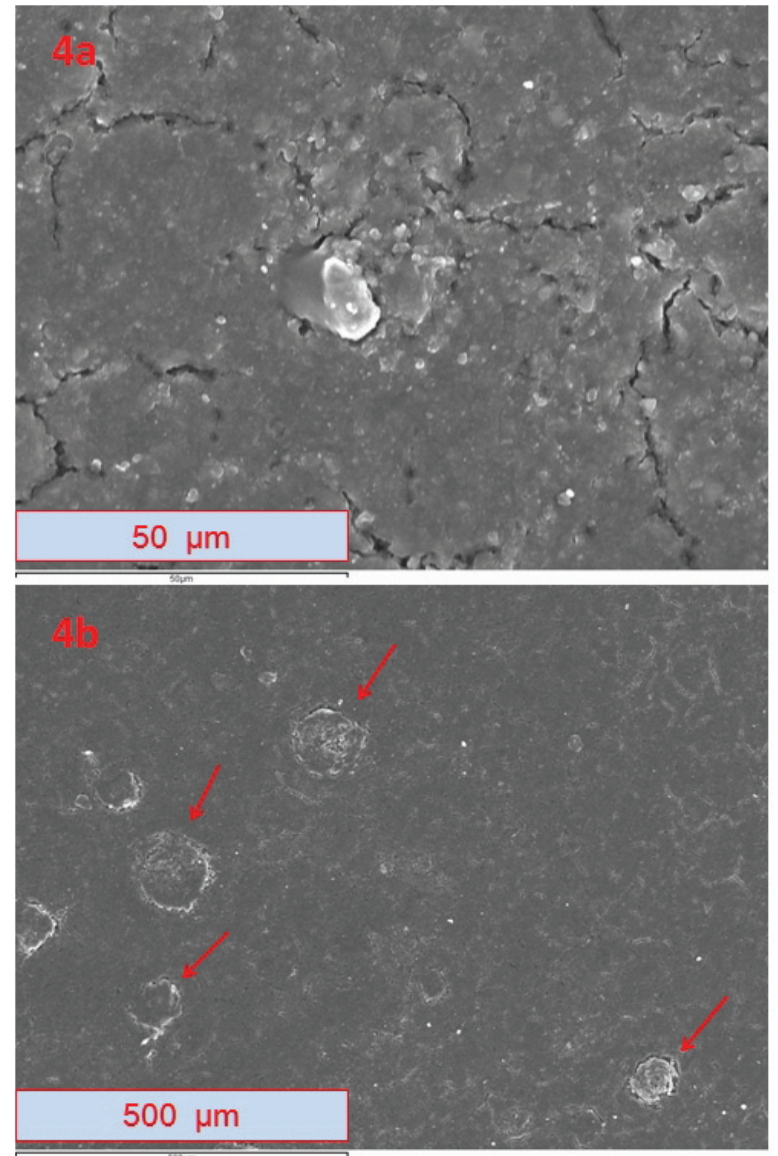

FIgURE 6. Micrographs of sample 4H-exposed, which were taken in (SE) mode with a resolution of 1024 x 786 pixels. Image (4a) shows the sample at 1000 magnification; image (4b),

shows the sample at 100 magnification. There are numerous cracks and fractures; micrograph (4b) additionally shows craters, which are marked with red arrows.

become stiffer and may suffer great damage from the impact of hail.

The effect of hail on waterproofing membranes in use has been already studied (29). The adverse effect of hail on a material's integrity was noted, indicating that this may be especially significant and decisive when it comes to an aged PVC-P.

The crater-like erosions were probably caused by relatively recent hail impacts on the surface of the polymer. It is highly unlikely that hail could cause significant damage to a relatively new PVC-P waterproofing membrane. One of the most important pathologies of an aged PVC-P is plasticizer loss (3). An unplasticized PVC-P waterproofing membrane cannot withstand hail impacts without any damage to its surface.

\subsection{Elemental analysis}

As a starting point, to ascertain the initial composition of the PVC-P waterproofing membrane, the elemental analysis of the original sample 
(5Original) is presented in Figure 7. The EDS spectrum signal shows the intensity (the counts or number of X-rays received and processed by the detector) on the Y-axis, and the energy level of those counts $(\mathrm{keV})$ on the $\mathrm{X}$-axis. Peaks labeled in the EDS spectrum (Figure 7) represent the chemical elements with significant presence (in mass percentage) in the elemental analysis. EDS analysis was performed at an accelerating voltage of $20 \mathrm{kV}$.

The data of the elemental analysis shown in Figure 7 are presented in mass percentage in Table 1.

The results presented in Figure 7 and Table 1 show the original composition of the polymer to be studied. The peaks possibly omitted at $0.880 \mathrm{keV}$, $2.137 \mathrm{keV}, 9.697 \mathrm{keV}, 11.454 \mathrm{keV}$ and $13.392 \mathrm{keV}$

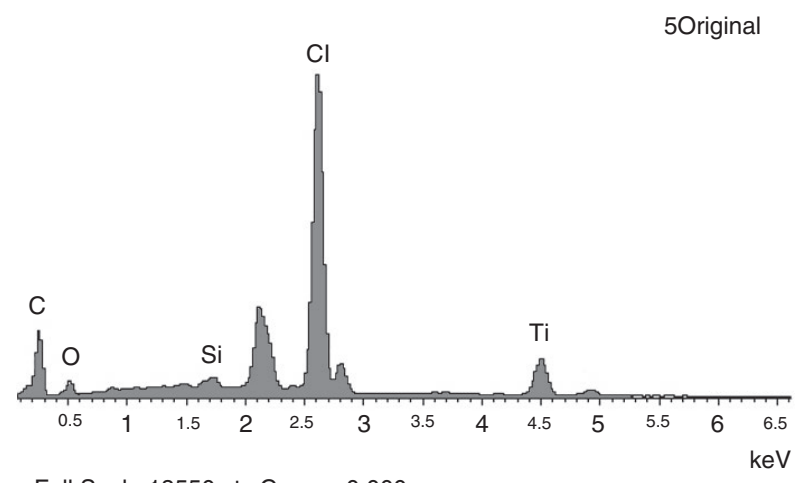

Full Scale 18550 cts Cursor: 0.000

FIGURE 7. EDS spectrum signal of the elemental analysis of sample 5Original. match with $\mathrm{Au}$, and they are directly related to the previous preparation of the samples (gold coating). In Figure 7, one of these peaks can be seen to the right of $\mathrm{Si}$ at $2.137 \mathrm{keV}$. These data are omitted when the results in mass percentage are presented.

The elemental analysis of the samples taken from the flat roof shows additional elements $(\mathrm{Ca}, \mathrm{Fe}$ and $\mathrm{Al}$ ), which appear due to contact with the urban environment (pollution, dust, etc.).

The results of the chemical composition of all of the samples extracted are presented and discussed in groups. The results of 3cXPSshaded and 2cXPSsunnyNOInter are compared in mass percentage with the results of 5Original in Table 2.

Although the results presented in Table 2 are relatively similar, there are small variations in the content of the chemical elements. Despite the differences in color of polymers 2cXPSsunnyNOInter and 3cXPSshaded, the chemical compositions are quite similar

TABLE 2. Comparison of the results in mass percentage of the elemental analysis of 5Original, 2cXPSsunnyNOInter and 3cXPSshaded

\begin{tabular}{lccc}
\hline Element & 5Original & $\begin{array}{c}\text { 2cXPSsunny } \\
\text { NOInter }\end{array}$ & $\begin{array}{c}\text { 3cXPS } \\
\text { shaded }\end{array}$ \\
\hline $\mathrm{C}$ & $63.53 \%$ & $62.01 \%$ & $62.50 \%$ \\
$\mathrm{O}$ & $9.77 \%$ & $9.24 \%$ & $7.19 \%$ \\
$\mathrm{Al}$ & & $0.27 \%$ & $0.22 \%$ \\
$\mathrm{Si}$ & $0.35 \%$ & $0.33 \%$ & $0.45 \%$ \\
$\mathrm{Cl}$ & $21.23 \%$ & $22.20 \%$ & $22.38 \%$ \\
$\mathrm{Ti}$ & $5.12 \%$ & $5.95 \%$ & $7.26 \%$ \\
\hline
\end{tabular}

TABLE 1. Results in mass percentage of the elemental analysis of sample 5Original

\begin{tabular}{l}
\hline Spectrum processing: \\
\hline Peaks possibly omitted: $0.880,2.137,9.697,11.454,13.392 \mathrm{keV}$ \\
Processing option: All elements analyzed (normalized) \\
\hline Number of iterations $=7$ \\
Standard: \\
\hline $\mathrm{C} \mathrm{CaCO} 3$ \\
$\mathrm{O} \mathrm{SiO} 2$ \\
$\mathrm{Si} \mathrm{SiO} 2$ \\
$\mathrm{Cl} \mathrm{KCl}$ \\
$\mathrm{Ti} \mathrm{Ti}$
\end{tabular}

\begin{tabular}{lccccc}
\hline Element & $\begin{array}{c}\text { App } \\
\text { Conc. }\end{array}$ & $\begin{array}{c}\text { Intensity } \\
\text { Corrn. }\end{array}$ & Weight $\%$ & $\begin{array}{c}\text { Weight } \% \\
\text { Sigma }\end{array}$ & Atomic\% \\
\hline $\mathrm{C}$ & 29.31 & 0.2607 & 63.53 & 0.76 & 79.92 \\
$\mathrm{O}$ & 4.74 & 0.2739 & 9.77 & 0.62 & 9.23 \\
$\mathrm{Si}$ & 0.62 & 0.9936 & 0.35 & 0.05 & 0.19 \\
$\mathrm{Cl}$ & 32.87 & 0.8752 & 21.23 & 0.41 & 9.05 \\
$\mathrm{Ti}$ & 7.14 & 0.7882 & 5.12 & 0.15 & 1.61 \\
Total & & & 100.00 & & \\
\hline
\end{tabular}


TABLE 3. Comparison of the results in mass percentage of the elemental analysis of 5Original, $4 \mathrm{H}$-exposed and 1cXPSsunnyInter

\begin{tabular}{lccc}
\hline Element & 5Original & $\begin{array}{c}\text { 4H- } \\
\text { exposed }\end{array}$ & $\begin{array}{c}\text { 1cXPSsunny } \\
\text { Inter }\end{array}$ \\
\hline $\mathrm{C}$ & $63.53 \%$ & $48.24 \%$ & $63.14 \%$ \\
$\mathrm{O}$ & $9.77 \%$ & $21.94 \%$ & $13.85 \%$ \\
$\mathrm{Al}$ & & $1.16 \%$ & $0.31 \%$ \\
$\mathrm{Si}$ & $1.93 \%$ & $0.61 \%$ \\
$\mathrm{Cl}$ & $0.35 \%$ & $17.15 \%$ & $16.94 \%$ \\
$\mathrm{Ca}$ & $21.23 \%$ & $0.33 \%$ & \\
$\mathrm{Ti}$ & & $8.43 \%$ & $5.15 \%$ \\
$\mathrm{Fe}$ & $5.12 \%$ & $0.82 \%$ & \\
\hline
\end{tabular}

to 5Original. The protection with the XPS board has kept the samples of PVC-P in a stable chemical condition that is very close to the original one. Despite having been covered with XPS, these samples did not show any sign of interaction with it.

Table 3 shows the results in mass percentage of the elemental analysis of samples $4 \mathrm{H}$-exposed and 1cXPSsunnyInter in comparison with the original sample (5Original).

The elemental analysis of sample $4 \mathrm{H}$-exposed shows a highly deteriorated polymer. The carbon content has decreased from $63.53 \%$ to $48.24 \%$. The backbone of a polymer is formed by a chain of carbon atoms. The chlorine content has decreased from $21.23 \%$ to $17.15 \%$, which clearly indicates a dehydrochlorination process in the polymer.

Variations in the mass percentage of carbon and chlorine (two fundamental elements for the polymer chain) are offset by the percentage of other elements such as titanium and oxygen, the value of which increases. In other words, the decline in the carbon and chlorine content is compensated by the remaining elements, which increase their presence in the total mass of the material.

The data show the overall deterioration of the polymer, including dehydrochlorination, which is clearly not the only degradation process taking place in the material. From 1950, different hypothesis and models have been proposed that attempt to explain the process of dehydrochlorination, at least in part. Even today, possible mechanisms of dehydrochlorination, such as thermal dehydrochlorination (30), are postulated. Dehydrochlorination is a complex phenomenon (19); therefore, the chemical process taking place in PCV-P degradation is not fully understood. Additionally, in the case of the increase in oxygen content, oxidative degradation reactions must be considered.

Oxidative degradation or degradation in the presence of oxygen (the case of the samples analyzed) is accompanied by a series of reactions, resulting in considerable changes in the molecular structure, composition and reactivity of PVC (31). The key processes are the diffusion of oxygen in the polymer matrix (oxygen absorption) and the chemical reaction between oxygen and macromolecular units.

Sample 1cXPSsunnyInter had been covered with XPS while it was in service. Additionally, however, in this area the XPS interacted with the PVC-P. In view of the results, the interaction between these materials had a significant effect on the chemical composition of the PVC-P. The chlorine content decreased from $21.23 \%$ to $16.94 \%$, which means the dehydrochlorination of this sample is slightly greater than that obtained in the analysis of sample $4 \mathrm{H}$-exposed. Dehydrochlorination could be the main mechanism of deterioration, since the percentage of carbon is practically the same.

Figure 8 shows a graph including all of the data expressed as mass percentage variation for the studied elements. The data in the figure show the content of carbon, oxygen, aluminum, silicon, chlorine, calcium, titanium and iron. The top part of the image shows a graphical representation of the results; the lower part shows the results of the chemical analysis.

\section{CONCLUSIONS}

Noteworthy deterioration factors for waterproofing membranes are UV radiation, thermal variations, frost cycles and high temperatures.

Exposure to the weather is one of the most damaging conditions for waterproofing membranes, particularly if they are placed in a horizontal position and in sunny areas.

Hail may have a harmful effect on the surface of aged waterproofing materials when they are placed horizontally.

In the long term, PVC-P waterproofing membranes exposed to natural weathering undergo significant deterioration in their molecular structure. The mass content of carbon and chlorine decreases substantially.

Carbon and chlorine loss has a remarkable effect on the polymer in a microscopic approach. Certainly, this condition has significant consequences for the mechanical properties of PVC-P waterproofing membranes.

Oxidative degradation of PVC-P waterproofing membranes takes place especially in layers exposed to the weather; however, interaction with XPS also increases oxygen content in the PVC-P membrane (an indication of oxidative degradation).

In areas in which there is a lack of interaction with the XPS, EDS analysis confirms good performance of the inverted flat roof for preserving the conditions of the PVC-P waterproofing membrane.

Interaction with XPS produces a significant decrease in the chlorine content of PVC-P waterproofing membranes. Thus, dehydrochlorination may be the main mechanism of deterioration. 


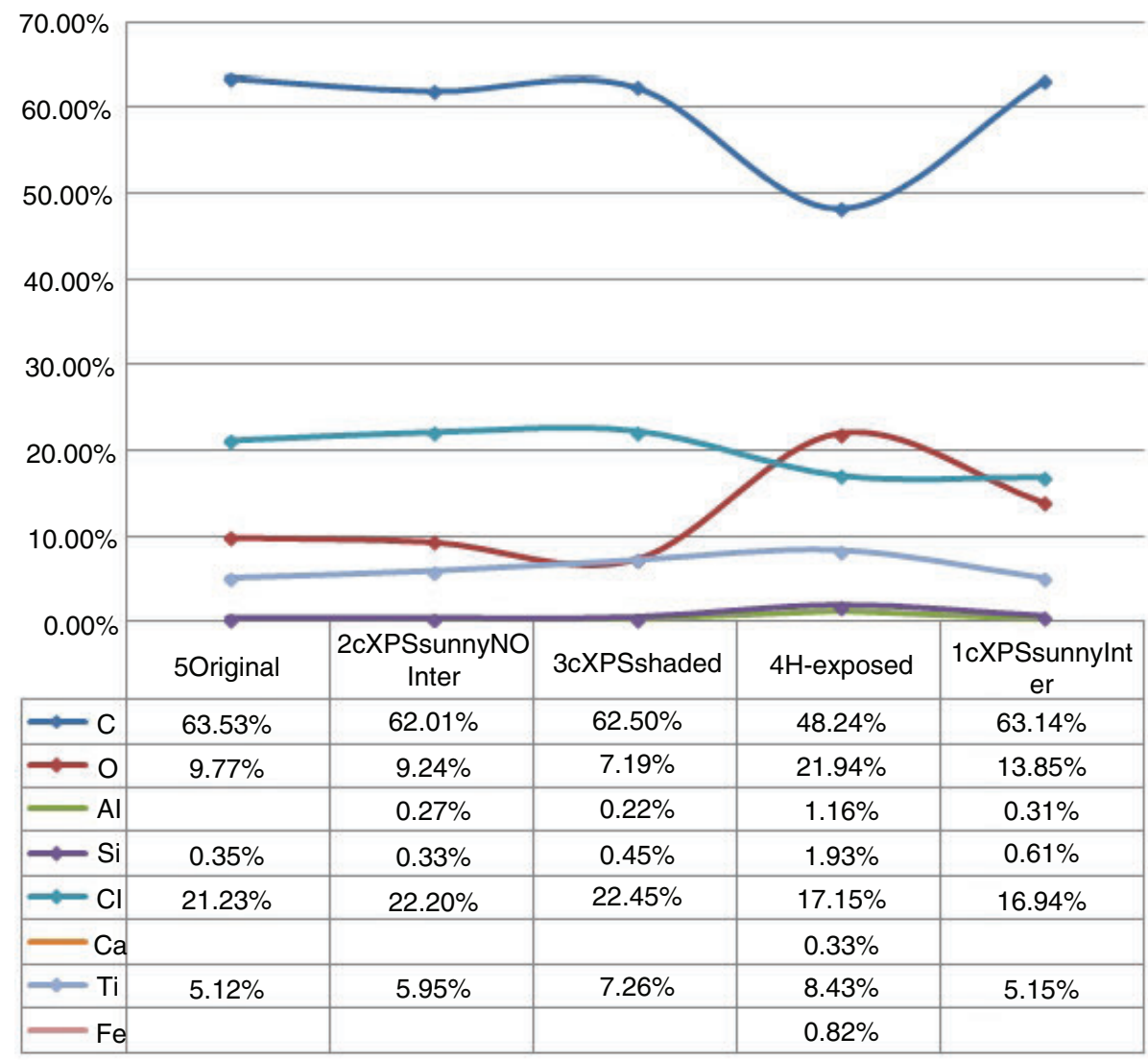

Figure 8. At the top, a graphical representation of the results of the elemental analysis in mass percentage. At the bottom, all of the data obtained in the analysis; the chemical elements shown are carbon, oxygen, aluminum, silicon, chlorine, calcium, titanium and iron.

Interaction with XPS implies significant phenomena in PVC-P waterproofing membranes: plasticizer migration, dehydrochlorination and oxidative degradation.

In general, waterproofing membranes must be separated from the XPS board in inverted flat roofs in order to extend the life cycle of this construction system.

\section{ACKNOWLEDGEMENTS}

The authors wish to thank Ana Maria Vicente Montaña for her assistance with the scanning electron microscopy at the National Center of Electron Microscopy (ICTS), Complutense University of Madrid, Spain.

\section{REFERENCES}

1. Marcilla, A.; Garcia, S.; Garcia-Quesada, J.C. (2008) Migrability of PVC plasticizers. Polymer Testing. 27 [2], 221233. http://dx.doi.org/10.1016/j.polymertesting.2007.10.007.

2. ASTM D883. (2012) Standard Terminology Relating to Plastics. Materials, American Society for Testing. ASTM International. www.astm.org. Philadelphia: Book of Standards. http://dx.doi.org/10.1520/D0883-12.
3. Pedrosa, A.; Del Río, M.; Fonseca, C. (2014) Interaction between plasticized polyvinyl chloride waterproofing membrane and extruded polystyrene board, in the inverted flat roof. Mater. Construcc., (CSIC), 64 [316]. http://dx.doi. org/10.3989/mc.2014.008913.

4. Navrátilová, R. K.; Jiránek, M.; Kačmaříková, V. (2015) The influence of long-term degradation of waterproof membranes on mechanical properties and on the radon diffusion coefficient - preliminary results. $J$. Clean. Product., 88, 369-375. http://dx.doi.org/10.1016/j. jclepro.2014.06.012.

5. Martin, J. W.; Embree, E.; P. Bentz, D.P. (1987) Effect of Time and Stress on the Time-to-Failure of EPDM T-Peel Joints. Proceedings, $8^{\text {th }}$ Conference on Roofing Technology: NRCA, 69-74.

6. Navratilova, R. K.; Jiranek, M.; Kokes, P; Wasserbauer, R.; Kacmarikova, V. (2014) Does long term exposure to radon gas influence the properties of polymeric waterproof materials? Radiat. Phys. Chem., 94, 58-61. http://dx.doi. org/10.1016/j.radphyschem.2013.05.054.

7. Jakubowicz, I. (2001) Effects of artificial and natural ageing on impact-modified poly(vinyl chloride) (PVC). Polym. Test. 20 [5], 545-551. http://dx.doi.org/10.1016/ S0142-9418(00)00074-X.

8. Ito, M.; Nagai, K. (2007) Analysis of degradation mechanism of plasticized PVC under artificial aging conditions. Polymer Degradation and Stability. 92 [2], 260-270. http:// dx.doi.org/10.1016/j.polymdegradstab.2006.11.003.

9. Jakubowicz, I.; Yarahmadi, N.; Gevert, T. (1999) Effects of accelerated and natural ageing on plasticized polyvinyl chloride (PVC). Polym. Degrad. Stabil. 66 [3], 415-421. http://dx.doi.org/10.1016/S0141-3910(99)00094-4. 
10. ASTM G154-12a. (2012) Standard Practice for Operating Fluorescent Ultraviolet (UV) Lamp Apparatus for Exposure of Nonmetallic Materials. ASTM International, West Conshohocken, PA. www.astm.org. Book of Standards. http://dx.doi.org/10.1520/G0154-12A.

11. ASTM D4329-13. (2013) Standard Practice for Fluorescent Ultraviolet (UV) Lamp Apparatus Exposure of Plastics. ASTM International, West Conshohocken, PA. www.astm.org. Book of Standards. http://dx.doi. org/10.1520/D4329

12. ISO 4892-2. (2013) Plastics - Methods of exposure to laboratory light sources. Part 2: Xenon - arc lamps. http:// dx.doi.org/10.3403/30096148.

13. Marques, J.A.; Lopes, J.G.; Correia, J.R. (2011) Durability of the adhesion between bituminous coatings and selfprotection mineral granules of waterproofing membranes. Construc. Build. Mat. 25 [1], 138-144. http://dx.doi. org/10.1016/j.conbuildmat.2010.06.047.

14. Pielichowski, K.; Njuguna, J. (2005) Thermal degradation of polymeric materials. Rapra Technology Limited, Shawbury, Shrewsbury, Shropshire, SY4 4NR, United Kingdom.

15. Yarahmadi, N.; Jakubowicz, I.; Martinsson, L. (2003) PVC floorings as post-consumer products for mechanical recycling and energy recovery. Polym. Degrad. Stabil. 79 [3], 439-448. http://dx.doi.org/10.1016/S0141-3910(02)00360-9.

16. Ocskay, G.Y. Lévai, J.; Nyitrai, Zs.; Szabados, E.; Várfalvi, F. (1974) The discolouration of PVC-I: Correlation between the dehydrochlorination and discolouration of PVC. Eur. Polym. J. 10 [12], 1121-1125. http://dx.doi. org/10.1016/0014-3057(74)90095-0.

17. Soudais, Y.; Moga, L.; Blazek, J.; Lemort, F. (2007) Coupled DTA-TGA-FT-IR investigation of pyrolytic decomposition of EVA, PVC and cellulose. J. Anal. Appl. Pyrol. 78 [1], 46-57. http://dx.doi.org/10.1016/j.jaap.2006.04.005.

18. IUPAC. (1977) Polyvinylchloride - 2. International Union of Pure and Applied Chemistry (Macromolecular Chemistry Division). A. Guyot. Main lectures presented at the Second International Symposium on Polyvinylchloride. Lyon Villeurbanne, Centre National de la Recherche Scientifique, Pergamon Press.

19. Sánchez-Jiménez, P.; Perejón, A.; Criado, J.M.; Diánez, M.J.; Pérez-Maqueda, L.A. (2010) Kinetic model for thermal dehydrochlorination of poly(vinyl chloride). Polymer. 51 [17], 3998-4007. http://dx.doi.org/10.1016/j.polymer.2010.06.020.

20. Ortega, J.J.; Blanco, M.; Cuevas, A. (1984) Acción de las radiaciones U.V. sobre el poli (cloruro de vinilo) flexible. Mater. Construcc., 196, 34. http://dx.doi.org/10.3989/ mc.1984.v34.i196.937.

21. Beer, H.R.; Delgado, A.H.; Paroli, R.M.; Graveline, S.P. (2005) Durability of PVC Roofing Membranes - Proof by Testing After Long Term Field Exposure. 10DBMC International Conference On Durability of Building
Materials and Components LYON, International AG, Industriestrasse, CH-6060 Sarnen, Switzerland.

22. Blanco, M.; Cuevas, A.; Aguiar, E. (2000) Patología de geomembranas de poli (cloruro de vinilo) plastificado instaladas como pantallas impermeabilizantes en embalses. Ingeniería civil. 119,91-101, 16, ${ }^{\circ}$ CSIC. Base de Datos ICYT.

23. Miyauchi, H.; Katou, N.; Tanaka, K. (2011) Behavior of a mechanically anchored waterproofing membrane system under wind suction and uniform pressure. Build. Environ. 46 [5], 1047-1055. http://dx.doi.org/10.1016/j. buildenv.2010.11.005

24. Silva, R.R.; Lopes, J.G.; Correia, J.R. (2010) The effect of wind suction on flat roofs: An experimental and analytical study of mechanically fastened waterproofing systems. Construc. Build. Mat. 24 [1], 105-112. http://dx.doi. org/10.1016/j.conbuildmat.2009.08.034.

25. Pedrosa, A.; Del Río, M.; Fonseca, C. (2012) Durability analysis of PVC-P membrane in inverted flat roof. Coinvedi, $2^{\text {nd }}$ International Conference on Construction and Building Research, Springer, 515-521, Escuela Técnica Superior de Ingeniería de Edificación, Universitat Politècnica de València. Valencia, Spain. http://dx.doi. org/10.1007/978-94-007-7790-3 62.

26. Pedrosa, A.; Del Río, M. (2013) Rehabilitation of flat roofs, concepts, minoration of incompatibilities and interactions. International Conference on Construction Research. Vivienda, pasado, presente y futuro. Instituto de Ciencias de la Construcción Eduardo Torroja, Madrid, Spain, CSIC, 173. http://digital.csic.es/bitstream/10261/108575/1/Abstracts_ and Proceedings \%20JORNADAS\%202013.pdf.

27. EN 13583 (2012) Flexible sheets for waterproofing. Bitumen, plastic and rubber sheets for roof waterproofing. Determination of hail resistance.

28. ASTM WK184 (2003) New Test Method for Determining Simulated Hail Damage Resistance of Roof Membranes. ASTM International, West Conshohocken, PA. www. astm.org.

29. Beer, H.R., Schumann, K., Flüeler, P. (2004) Hail Resistance Of Aged PVC Roofing Membranes - A Field Evaluation Of Roofs Ranging Between 15 And 34 Years. $C I B$ World Building Congress, "Building for the Future", Toronto, Canada.

30. Wang, Y.; Wang, X.; Liu, L.; Peng, X. (2009) Theoretical study on the thermal dehydrochlorination of model compounds for poly(vinyl chloride). J. Mol. Struct: THEOCHEM. 896 [1-3], 34-37. http://dx.doi.org/10.1016/j. theochem.2008.10.047.

31. Migallón, A. J. (1996) Características de la degradación térmica de los plastisoles vinílicos. Tesis doctoral de la Universidad de Alicante, Facultad de Ciencias, Departamento de Química Analítica. http://hdl.handle. net $/ 10045 / 3652$. 